\title{
Sensibilidad antimicrobiana y detección de genes de virulencia en aislados clínicos de Shigella spp.
}

\author{
Irina Villacrés ${ }^{1}$, Iliana Alcocer ${ }^{1}$, Jeannete Zurita ${ }^{2}$ y Mercedes Rodríguez-Riglos ${ }^{1}$ \\ ${ }^{1}$ Laboratorio de Microbiología, Escuela de Ciencias Biológicas, \\ Pontificia Universidad Católica del Ecuador, Quito, Ecuador, iralcocer@puce.edu.ec \\ ${ }^{2}$ Facultad de Medicina, Pontificia Universidad Católica del Ecuador, Quito, Ecuador.
}

Recibido: 2015-08-07; aceptado: 2015-10-05

\begin{abstract}
RESUMEN.- El género Shigella comprende las especies S. flexneri, S. sonnei, S. boydii y S. dysenteriae, bacterias responsables de la shigelosis. Éste género se caracteriza por la presencia de multirresistencia a antibióticos y una variedad de factores de virulencia que permiten la infección al hospedero. El objetivo de este estudio fue establecer la sensibilidad antimicrobiana y detectar genes de virulencia "Invasion plasmid antigen $\mathrm{H}^{\prime}$, ipaH; "Invasion-associated locus", ial; "Shigella toxin" Stx; "Shigella enterotoxin 1A", set1A; y "Shigella enterotoxin 1B", set1B en aislados clínicos de Shigella spp. Se analizaron 79 aislados obtenidos de Zurita \& Zurita Laboratorios y del hospital Vozandes. Mediante serotipificación, se registraron tres especies: S. flexneri $(64.6 \%)$, S. sonnei $(29.1 \%)$, y S. boydii $(6.3 \%)$. La sensibilidad antimicrobiana siguió el método de difusión con disco según las recomendaciones del Clinical and Laboratory Standars Institute (CLSI). La resistencia obtenida fue a tetraciclina $(96.20 \%)$, ampicilina (94.9\%), trimetoprima/ sulfametoxazol $(86.1 \%)$ y cloranfenicol $(84.8 \%)$. No se registraron aislados de Shigella con resistencia a ciprofloxacino, azitromicina ni a ceftriaxona. Se determinó la presencia de genes de virulencia por la reacción en cadena de la polimerasa (PCR). Se determinó una alta prevalencia de los genes ipaH (91.1 \%) e ial (82.3\%), los genes codificantes de enterotoxina 1 ( $\operatorname{set} 1 A$ y set $1 B$ ) se encontraron en un $35.4 \%$. Los resultados obtenidos demuestran la existencia de multirresistencia a antibióticos y cepas virulentas.
\end{abstract}

PALABRAS CLAVES: enterotoxinas, genes de virulencia, resistencia antimicrobiana, serogrupos, Shigella spp.

ABSTRACT.- The genus Shigella includes S. flexneri, S. sonnei, S. boydii and S. dysenteriae, which are producers of shigelosis. The genus are characterized due to multidrug resistance to antibiotics and a variety of virulence factors that allow the infection to host. The objective of this study was to establish the antibiotic susceptibility and detection of virulence genes in clinical isolates of Shigella spp.: invasion plasmid antigen H (ipaH), invasion-associated locus (ial), Shigella toxin $(S t x)$, Shigella enterotoxin 1A $(\operatorname{set1A})$, and Shigella enterotoxin 1B (set1B). We analyzed 79 strains from "Zurita \& Zurita Laboratorios" and "Hospital Vozandes". Three species were identified: S. flexneri (64.6\%), S. sonnei $(29.1 \%)$, and S. boydii (6.3 \%) by antiserum agglutination. The antimicrobial susceptibility was performed by following the disk diffusion method and recommendations of the Clinical and Laboratory Standards Institute (CLSI). High resistance was observed to tetracycline $(96.2 \%)$, ampicillin (94.9\%), trimethoprim/sulfamethoxazole $(86.1 \%)$, and chloramphenicol $(84.8 \%)$. No resistance was identified to ciprofloxacin, ceftriaxone and azitromicin. The analysis of the presence of virulence genes was performed using the Polymerase Chain Reaction (PCR). A high prevalence of genes ipaH (91.1\%) and ial $(82.3 \%)$ was determined, the encoding genes of enterotoxin 1 (set 1 and set1B) were found in $35.4 \%$ of the isolates. The results demonstrate the existence of multidrug resistances to antibiotics and virulent strains of the genus Shigella.

KEYWORDS: antimicrobial resistance, enterotoxins, serogroups, Shigella spp., virulence genes.

\section{INTRODUCCIÓN}

El género Shigella (Shiga, 1989) comprende bacilos Gram negativos de 0.3 a $1.0 \mu \mathrm{m}$ diámetro y de 1 a $6 \mu \mathrm{m}$ de longitud, no móviles, no formadores de esporas, anaerobios facultativos, pertenecientes a la familia Enterobacteriaceae (Terragno et al., 2007). Las cuatro especies del género Shigella que provocan todas las manifestaciones clínicas de la shigelosis, que pueden causar desde diarrea acuosa hasta diarrea exudativa fulminante, son Shigella dysenteriae, Shigella flexneri, Shigella boydii y 
Shigella sonnei. La enfermedad más grave resulta de la infección causada por las especies $S$. dysenteriae tipo 1. Se considera que la cepas de S. flexneri son menos virulentas, mientras que, las de $S$. boydii y $S$ sonnei, generalmente, originan episodios autolimitados de diarrea acuosa con fiebre. No se ha establecido hasta el momento la razón por la cual en los países industrializados predominan las infecciones por cepas se $S$. sonnei y $S$. boydii, mientras que, los aislamientos de $S$. dysenteriae y $S$. flexneri son característicos de los países en vías de desarrollo (Zurita, 2012).

Su identificación se fundamenta en características bioquímicas y antigénicas, en base a ellas se describen cuatro especies: Shigella dysenteriae (Shiga, 1898), perteneciente al serogrupo A; Shigella flexneri (Flexner, 1900), concerniente al serogrupo B; Shigella boydii (Boyd, 1938), perteneciente al serogrupo C; y, Shigella sonnei (Sonne, 1915), perteneciente al serogrupo D. Los grupos A, B y $\mathrm{C}$ se subdividen en serotipos (número arábigo) y subtipo (letra minúscula) que son 12, 14 y 18, respectivamente. El grupo D tiene un solo serotipo. Todas ellas pueden causar disentería bacilar, aunque con diferente gravedad (Zurita, 2012).

La Organización Mundial de la Salud (2010) estima la ocurrencia de 165 millones de casos y 1.1 millones de muertes por año, de las cuales alrededor de 576000 son de niños menores de 5 años de edad.

La transmisión de estas bacterias se produce principalmente por ruta fecal-oral directa o indirecta en lugares que se caracterizan por una higiene deficiente (Kotloff et al., 1999). La infección surge posteriormente a la ingestión de 10 a 100 microorganismos y los síntomas se presentan de 12 a 96 horas relativas al período de incubación de la bacteria (Mandell et al., 2009).

La shigelosis es una enfermedad diarreica aguda autolimitada, sin embargo, hay condiciones en las cuales se encuentra establecido el tratamiento cuyo objetivo principal es bajar la carga microbiana y la intensidad de los síntomas. Se recomienda el uso de ceftriaxona en lactantes menores de 6 meses que requieran hospitalización así como ciprofloxacino en adultos mayores con deshidratación severa. Debido a que el inóculo es muy bajo, también se recomienda tratamiento en los casos de hacinamiento (Zurita, 2012).

El género Shigella presenta una variedad de factores de virulencia que le permiten el ingreso a la mucosa gástrica, evadiendo las defensas del hospedero. Varios de estos factores han sido asociados al género Shigella, los más relevantes en este estudio son los que intervienen en la invasión y colonización del epitelio intestinal como los genes ipaH (invasión plasmid antigen $\mathrm{H}$ ), que permite la diseminación facilitada de Shigella a través de la mucosa y la inhibición de la coagulación inducida por trombina que provoca la eliminación de sangre en las heces (Hale, 1991) e ial (invasión-associated locus) que promueve la internalización e invasión del tejido "blanco" gracias a la producción de adhesinas e invasinas y permite la diseminación intercelular de la bacteria y el traslado y secreción de diversos factores de virulencia (Noriega et al., 1999). El gen ipaH conocido como "invasión plasmid antigen $\mathrm{H}^{\prime \prime}$ ha sido observado en el 99 $\%$ de aislados de Shigella, determinándose como el gen más estable de detectar debido a que se encuentra en el cromosoma y en el ADN plasmidial en múltiples copias (Lin Thong et al., 2005).

La enterotoxina 1 (ShET-1), es una proteína codificada en el cromosoma bacteriano por los genes $\operatorname{set1A}$ (subunidad A de la proteína) de 309 pb y set1B (subunidad B de la proteína) de $147 \mathrm{pb}$. La importancia de la enterotoxina 1 en la virulencia de Shigella se ha descrito más recientemente. Esta toxina parece relacionarse con la fase temprana de la diarrea acuosa en la shigelosis, expresándose con mayor frecuencia en S. flexneri 2a. Sin embargo, el mecanismo por el cual inicia la diarrea durante la shigelosis aún no está claramente definido (Vargas et al., 1999).

Otro factor de virulencia es la exotoxina Shiga, que es liberada únicamente durante la lisis celular. Su efecto es bloquear la síntesis proteica en la célula eucariota (Henhly et al., 1996). La exotoxina Shiga es una enterotoxina que se asocia con el serotipo A1 de $S$. dysenteriae. Esta exotoxina es codificada por el gen Stx de 895 pb. La principal complicación de la liberación de la toxina Shiga es el desarrollo del Síndrome Urémico Hemolítico.

Por lo expuesto, el objetivo fue establecer la sensibilidad antimicrobiana y detectar genes de virulencia $i p a H, i a l, S t x, \operatorname{set} 1 A$ y set $1 B$ en aislados clínicos de Shigella spp., por medio de pruebas fenotípicas y genotípicas.

\section{MATERIALES Y MÉTODOS}

Población de estudio.-El presente estudio incluyó un total de 79 aislados clínicos de Shigella spp., obtenidos en Zurita \& Zurita Laboratorios (Quito, Ecuador) y del hospital Vozandes en Quito. Fueron colectados durante el año 2005 al año 2010. Las muestras provienen de procesos infecciosos documentados. 
Los aislados se mantienen en la Colección Bacteriana Quito Católica, CB-QCA del Laboratorio de Microbiología en la Escuela de Ciencias Biológicas con registro de los códigos hospitalarios, fechas de aislamiento, origen de los aislados, sexo y edad de los pacientes.

Identificación bioquímica del género Shigella.El género Shigella de acuerdo con sus reacciones bioquímicas se identifica como un bacilo no mótil, no fermentador de lactosa, productor o no de ornitina descarboxilasa según la especie, no productor de triptofanasas y que presenta una fermentación butilén-glicólica. Para evidenciar este perfil se realizaron las pruebas bioquímicas estándares: agar con triple azúcar y hierro (TSI), motilidad, indol, ornitina (MIO) y rojo de metilo (RM) / Vogues-Proskauer (VP), a partir de colonias aisladas en agar entérico Hecktoen (Difco, 2003).

Identificación serológica de las especies del género Shigella.- La serotipificación se realizó mediante la técnica de aglutinación en lámina propuesta por Edwars y Edwing (1972) y conforme a las recomendaciones del Manual Difco Shigella O Antisera (2011). Mediante esta técnica se puso en evidencia la presencia de antígenos somáticos $\mathrm{O}$ enfrentando el antisuero polivalente (anticuerpo) con la bacteria (antígeno). Las cepas fueron enfrentadas con los cuatro antisueros policlonales comerciales Difco Shigella Antisera Poly de serogrupos: Grupo A, S. dysenteriae, serotipos 1-7; Grupo B, S. flexneri, serotipos 1-6; Grupo C, S. boydii, serotipos 1-7; y, Grupo D, S. sonnei, serotipos I y II. Para la utilización de los antisueros policlonales y la validación de los resultados, se realizaron controles positivos y negativos. Para el control positivo se utilizaron las cepas American Type
Culture Collection, ATCC: S. sonnei 25931; S. boydii (1) 9207; y S. flexneri (2b) 12022. Para los controles negativos se utilizó una gota de cloruro de sodio al $0.85 \%$ y la cepa Escherichia coli ATCC 25922.

Sensibilidad a los antimicrobianos.- Para este procedimiento fue utilizado el método de difusión con disco (Bauer et al., 1966) en agar Müller-Hinton (Difco ${ }^{\mathrm{TM}}$ ) con sujeción a las recomendaciones propuestas por el Clinical and Laboratory Standars Institute (CLSI, 2015).

Detección molecular de genes de virulencia en Shigella spp.- La extracción del ADN total se realizó con el empleo del método sugerido por Carvalho et al. (2001). La confirmación de la integridad del ADN para la realización de la reacción en cadena de la polimerasa PCR fue realizada mediante la amplificación del gen codificante de la subunidad $16 \mathrm{~S}$ del ribosoma bacteriano. Los iniciadores utilizados para la amplificación del gen 165 descritos por Malhotra-Kumar et al. (2005) se encuentran detallados en la Tabla 1. Para medir el peso molecular de las bandas obtenidas se utilizaron 100 bp DNA Ladder Tracklt ${ }^{\mathrm{TM}}$ (Invitrogen). Como control negativo se utilizó agua de grado molecular y como control positivo para el gen $16 \mathrm{~S} \mathrm{ARNr}$ se empleó la cepa S. flexneri ATCC (2b) 12022.

El ciclo de amplificación del gen 16S fue llevado a cabo en un termociclador Labnet Multigene Model TC9600-G programando un ciclo de desnaturalización inicial a $93^{\circ} \mathrm{C}$ por 3 minutos, seguido de 27 ciclos, los cuales consistieron en un paso de desnaturalización a $93^{\circ} \mathrm{C}$ por 30 segundos, seguido de un paso de anillamiento a $59.3^{\circ} \mathrm{C} 45$ segundos, y un último paso de extensión a $65^{\circ} \mathrm{C}$ por 45 segundos; finalmente un

Tabla 1. Iniciadores utilizados para la identificación de varios genes asociados a mecanismos de virulencia en Shigella spp y el 16S.

\begin{tabular}{|c|c|c|c|c|}
\hline Iniciador & $\begin{array}{c}\text { Gen de } \\
\text { virulencia }\end{array}$ & Secuencia de nucleótido ( $5^{\prime}$ a $\left.3^{\prime}\right)$ & $\begin{array}{c}\text { Tamaño } \\
\text { Amplicón (pb) }\end{array}$ & Referencia \\
\hline 16S rRNA F & rrs & GAGTACGACCGCAAGGTTGA & 100 & Malhotra-Kumar et al. (2005) \\
\hline $16 \mathrm{~S}$ rRNA R & rrs & CTGGTAAGGTTCTTCGCGTTG & 100 & Malhotra-Kumar et al. (2005) \\
\hline ShET1AF & $\operatorname{set} 1 \mathrm{~A}$ & TCACGCTACCATCAAAGA & 309 & Fusano et al. (1995) \\
\hline ShET1AR & & TATCCCCCTTTGGTGGTA & & \\
\hline ShET1BF & set1B & GTGAACCTGCTGCCGATATC & 147 & Fusano et al. (1995) \\
\hline ShET1BR & & ATTTGTGGATAAAAATGACG & & \\
\hline ialR & ial & CTGGATGGTATGGTGAGG & 320 & Frankel et al. (1989) \\
\hline ialR & & GGAGGCCAACAATTATTTCC & & \\
\hline Shig1 & ipaH & TGGAAAAACTCAGTGCCTCT & 423 & Lüscher y Altewegg (1994) \\
\hline Shig2 & & CCAGTCCGTAAATTCATTCT & & \\
\hline StxF & Stx & CAGTTAATGTGGTTGCGAAG & 895 & Frankel et al. (1989) \\
\hline StxFR & & CTGCTAATAGTTCTGCGCATC & & \\
\hline
\end{tabular}


ciclo de extensión a $72^{\circ} \mathrm{C}$ durante 5 minutos. Los productos resultantes de la reacción en cadena de la polimerasa fueron almacenados a $-20^{\circ} \mathrm{C}$ hasta su análisis electroforético.

Para la identificación de genes de virulencia en Shigella spp., se emplearon los iniciadores previamente descritos por Fusano et al. (1995) y Lüscher y Altewegg (1994) los cuales se encuentran detallados en la Tabla 1.

Para la reacción en cadena de la polimerasa se usó el ADN total. Las condiciones de amplificación utilizadas son descritas por Lin Thong et al. (2005) y Vargas et al. (1999). Como control negativo se utilizó agua de grado molecular en lugar de ADN y como control positivo para todos los genes en estudio se empleó la cepa CB-QCA 3349 Shigella flexneri pues este aislado posee cuatro de los cinco genes en estudio: $i p a H$, ial, $\operatorname{set} 1 A$ y $\operatorname{set} 1 B$.

La PCR fue estandarizada en un volumen de 25 $\mu \mathrm{l}$, que contiene: $12.5 \mu \mathrm{l}$ de Green $0.4 \mathrm{mM}$ de cada iniciador (Invitrogen) y $1 \mu \mathrm{l}$ de ADN.

El programa de amplificación de los genes se realizó en un termociclador Labnet Multigene Model TC9600-G. Se inició el programa de PCR con una desnaturalización inicial de $95^{\circ} \mathrm{C}$ por 5 minutos, seguido de 30 ciclos con una desnaturalización a $95^{\circ} \mathrm{C}$ durante 50 segundos, anillamiento, para los genes ipaH, ial, y set $1 B$ a $52^{\circ} \mathrm{C}$ por 1.5 minutos; para el gen set $1 A$ a $48^{\circ} \mathrm{C}$ por 1.5 minutos; para el gen $S t x$ a $55^{\circ} \mathrm{C}$ por 1.5 minutos; y, extensión a $72^{\circ} \mathrm{C}$ durante 2 minutos, seguido de un ciclo de extensión final a $72^{\circ} \mathrm{C}$ por 7 minutos.

El peso molecular de las bandas obtenidas para cada gen fue estimado visualmente mediante el uso de 100 bp DNA Ladder Tracklt ${ }^{\mathrm{TM}}$ (Invitrogen).

Análisis de los productos de amplificación.- Los productos de PCR fueron analizados mediante electroforesis horizontal en geles de agarosa al 1.0 \% en tampón TBE 1 X (89 mM de Tris, 89 mM de ácido bórico y $2.50 \mathrm{mM}$ de EDTA). El programa de electroforesis consistió en la aplicación de $8 \mathrm{~V} / \mathrm{cm}$ durante 45 minutos en tampón TBE 0.5 X. La tinción del gel se realizó con el empleo de SYBRGold (Invitrogen). Los resultados fueron documentados en el sistema de captura de imágenes MiniBis Pro (DNR Bio- Imaging Systems) con la ayuda del programa informático GelCapture 4.5.3.

Validación de los genes de virulencia.- Para validar el protocolo de amplificación y confirmar la identidad de la cepa se utilizó como control el aislado
CB-QCA 3349 Shigella flexneri que posee cuatro de los cinco genes en estudio: ipaH, ial, set1A y set1B. Los productos de PCR fueron enviados a Macrogen Korea para su secuenciamiento. Las muestras fueron purificadas a partir de gel de agarosa con la utilización del Kit Wizard @ SV Gel and PCR CleanUp System. Las secuencias fueron editadas con el programa Genius versión 7.0 y alineadas con las secuencias depositadas en el GENBANK mediante la utilización de la herramienta BLAST.

Análisis estadístico.- El análisis porcentual de los resultados se realizó medianteel empleo de Microsoft Office Excel 2010 (@2010 Microsoft Corporation). Para el estudio de los resultados obtenidos tanto en la serotipificación como en la presencia de genes de virulencia, y resistencia a antimicrobianos, se utilizó el método estadístico de análisis de correspondencias múltiples (MCA), con el cual se determinó la contribución de varios factores en un simple evento o resultado, mediante la comparación de los diferentes serotipos utilizados, con la presencia de genes y la resistencia a antibióticos individualmente. Para este análisis se empleó el programa estadístico informático "Statistical Package for the Social Sciences" (SPSS) versión 12.0.

\section{RESULTADOS}

Población de estudio.- De los 79 aislados, 61 muestras $(77.20 \%)$ fueron obtenidas a partir de heces, 18 muestras $(22.8 \%)$ a partir de secreciones vaginales.

Identificación serológica de las especies del género Shigella.- Por medio del método de aglutinación en lámina se obtuvo la identificación de las especies del género Shigella, obteniéndose 51 aislados (64.6 $\%$ ) positivos para Shigella flexneri, 23 aislados (29.1 $\%)$ para Shigella sonnei, 5 aislados $(6.3 \%)$ positivos para Shigella boydii, y $0 \%$ de aislados positivos para Shigella dysenteriae (Figura 1).

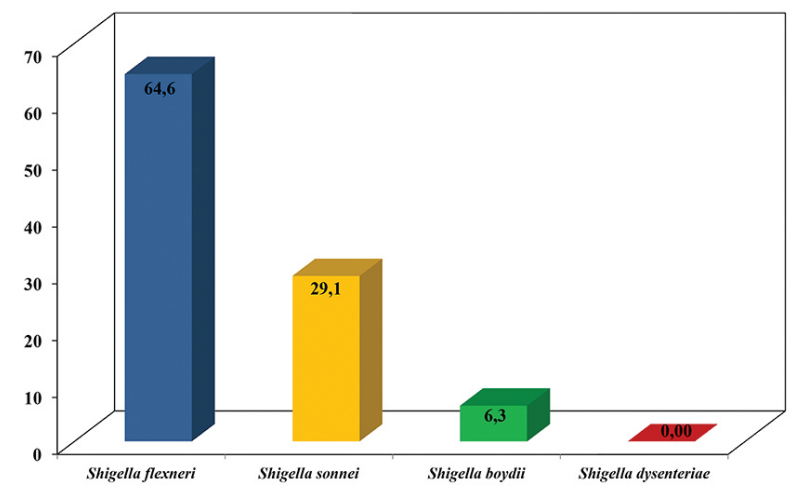

Figura 1. Porcentaje de identificación de las diferentes especies en la población total de aislados de Shigella spp. N=79 
De los 51 aislados de Shigella flexneri, $33(64.7 \%)$ fueron aislados de heces y $18(35.3 \%)$ de secreción vaginal. De los 23 aislados de Shigella sonnei, 23 (100\%) fueron aislados de heces. De los 5 aislados de Shigella boydii, también el $100 \%$ fueron aislados de heces.

Sensibilidad a los antimicrobianos.- La sensibilidad a antimicrobianos obtenida para los diferentes antibióticos enfrentados con los aislados de Shigella spp., se observa en la Figura 2. Analizando globalmente el género, se observó que 76 aislados $(96.2 \%)$ presentan una resistencia a tetraciclina, 75 aislados $(94.9 \%)$ fueron resistentes a ampicilina, 68 aislados ( $86.1 \%$ ) fueron resistentes a trimetoprima/sulfametoxazol, 67 aislados $(84.8 \%)$ presentaron resistencia a cloranfenicol, 7 aislados (8.9\%) fueron resistentes a ácido nalidíxico, 4 aislados $(5.1 \%)$ presentaron resistencia a nitrofurantoina y no se encontró aislamientos con resistencia a ciprofloxacino, azitromicina ni a ceftriaxona, (Figura 2). Como control positivo fue incluido el análisis de las cepas ATCC: S. sonnei 25931, S. boydii (1) 9207 y S. flexneri (2b) 12022, las cuales mostraron sensibilidad a todos los antibióticos utilizados.

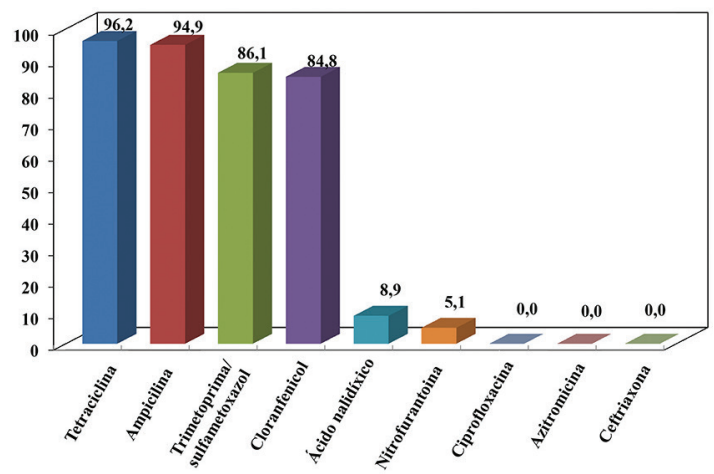

Figura 2. Porcentaje de resistencia a antibióticos dentro de la población de Shigella spp. $\mathrm{N}=79$

Detección molecular de los genes de virulencia en Shigella spp.- Para el gen $16 \mathrm{~S}$ ARNr se obtuvo un $98 \%$ de identidad, para el gen ipaH se obtuvo un $100 \%$ de identidad, para el gen $i a l$ se obtuvo el 99 $\%$ de identidad en un total de 10 secuencias donde se producen alineamientos significativos, para el gen set1 $A$ se obtuvo $100 \%$ de identidad y para el gen set $1 B$ se obtuvo un $99 \%$ de identidad.

Análisis de presencia o ausencia de genes de virulencia.- El análisis de la presencia de los genes fue evidenciado mediante la amplificación en gel de agarosa obteniéndose las bandas con el peso específico para cada gen estudiado (Figura 3).

Los resultados obtenidos para el total de 79 indican que 72 aislados $(91.1 \%)$ presentaron el gen ipaH,

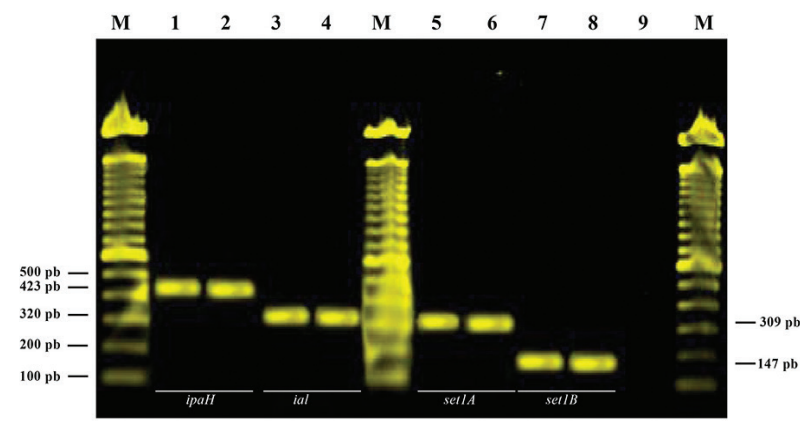

Figura 3. Representación fotográfica en gel de agarosa de la amplificación de los genes ipaH, ial, set1A y set1B en Shigella spp. M, marcador de peso molecular (100pb); Pocillo 1, control positivo gen ipaH cepa CB-QCA 3349 Shigella flexneri; Pocillo 2, muestra positiva de Shigella spp. para el gen ipaH; Pocillo 3, control positivo gen ial cepa CB-QCA 3349 Shigella flexneri; Pocillo 4, muestra positiva de Shigella spp. para el gen ial; Pocillo 5, control positivo gen set1A cepa CB-QCA 3349 Shigella flexneri; Pocillo 6, muestra positiva de Shigella spp. para el gen set1A; Pocillo 7, control positivo gen set1B cepa CB-QCA 3349 Shigella flexneri; pocillo 8, muestra positiva de Shigella spp. para el gen set1B; Pocillo 9, control negativo, agua de grado molecular.

el gen ial se presentó en 65 aislados $(82.3 \%), 47$ aislados $(59.5 \%)$ presentaron el gen set1B y 32 aislados $(40.5 \%)$ el gen set1A. Ningún aislado evidenció presencia del gen Stx (Figura 4). Seis aislados $(7.6 \%)$ no presentaron ningún gen de los analizados en este estudio.

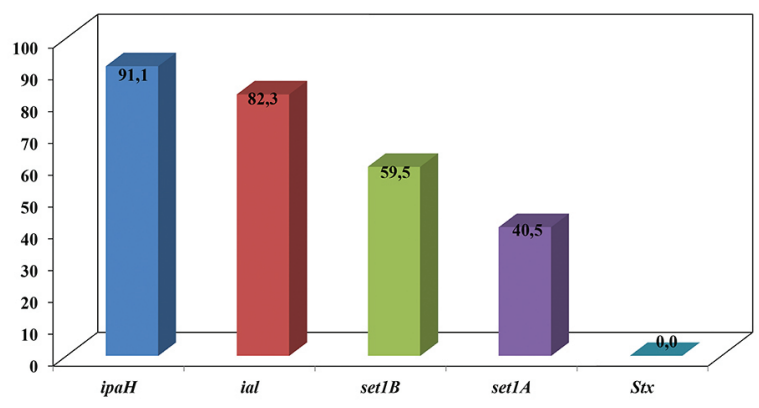

Figura 4. Porcentaje de presencia de los genes set1A, set1B, ial, ipaH y Stx en la población total de aislados de Shigella spp. N=79

Según el análisis estadístico existe alta heterogeneidad en los patrones de resistencia al relacionarlos con las especies con una concentración superior de casos de $S$. flexneri multirresistentes en relación con las otras especies.

La presencia de los cuatro genes ipaH, ial, set1A y set1 $B$ en conjunto se encuentra exclusivamente en S. flexneri. Para S. sonnei se observó una mayor concentración de casos con presencia de genes set1A y set1B. En el caso de $S$. boydii se observó una mayor presencia del gen ial.

En la Tabla 2 se encuentran en detalle los patrones de virulencia en Shigella. Shigella flexneri tiene 
principalmente el patrón de virulencia 1 con la presencia de los genes ipaH, ial, set1 $A$ y set1B con 28 aislados que indican la producción de la enterotoxina 1 ( $\operatorname{set} 1 A$ y $\operatorname{set} 1 B)$, la producción de los genes de la invasión y colonización del epitelio intestinal $(i p a H)$ y de la producción de adhesinas e invasinas que permiten la diseminación intercelular de la bacteria (ial). En esta especie todos los aislados presentaron el gen ipaH excepto 4 aislados que no tuvieron ningún gen. En la especie S. sonnei el patrón de virulencia prevalente fue el 4 con la presencia de los genes ipaH, ial y set1B en 11 aislados. En esta especie todos los aislados presentaron el gen ipaH excepto 2 aislados que no tuvieron ningún gen. Finalmente en la especie $S$. boydii se vio principalmente el patrón de virulencia $i p a H, \operatorname{set1B}$, ial y el patrón ipaH, ial. Todos los aislados en esta especie tuvieron el gen ial.
Entre los marcadores fenotípicos la serotipificación es el método de mayor agudeza para la especiación del género Shigella. Este método permite realizar estudios de vigilancia que determinen la prevalencia de serogrupos y serovariedades en diferentes zonas geográficas, ya sea en estudios de brotes o de casos esporádicos (Guerrant et al., 1999). En este estudio se utilizó con el $100 \%$ de éxito el método de serotipificación en los aislados de Shigella se obtuvo la presencia de las especies $S$. flexneri, S. sonnei y $S$. boydii. No se han registrado en revistas indexadas, hasta la fecha, cepas de $S$. dysenteriae en el Ecuador ni en 10 años de vigilancia de la resistencia (Zurita, 2012). En este estudio, mediante serología, no se identificó $S$. dysenteriae.

Estudios relativos a la identificación de especies dentro del género Shigella han determinado que

Tabla 2. Patrones de virulencia mostrados por los aislados de Shigella spp.

\begin{tabular}{|c|c|c|c|c|c|c|}
\hline \multirow[b]{2}{*}{ Genotipos de virulencia } & \multirow[b]{2}{*}{ Patrón } & \multicolumn{3}{|c|}{ Especies } & \multirow[b]{2}{*}{ Total de cepas } & \multirow[b]{2}{*}{$\%$} \\
\hline & & S. flexneri & S. sonnei & S. boydii & & \\
\hline 1 & ipaH,set1A,set1B, ial & 28 & & & 28 & 35.4 \\
\hline 2 & ipaH, ial & 7 & 7 & 2 & 16 & 20.3 \\
\hline 3 & ipaH, set1A, ial & 1 & & & 1 & 1.3 \\
\hline 4 & ipaH, set1B, ial & 6 & 11 & 2 & 19 & 24.1 \\
\hline 5 & ipaH, set1A & 2 & 1 & & 3 & 3.8 \\
\hline 6 & ipaH & 3 & 2 & & 5 & 6.3 \\
\hline 7 & ial & & & 1 & 1 & 1.3 \\
\hline 8 & ninguno & 4 & 2 & & 6 & 7.6 \\
\hline Total & & 51 & 23 & 5 & 79 & 100.0 \\
\hline
\end{tabular}

ipaH, invasión plasmid antigen $\mathrm{H}$; ial, invasión-associated locus; set1A, enterotoxina 1-subunidad A; set1B, enterotoxina 1-subunidad B.

\section{DISCUSIÓN}

Las enfermedades diarreicas a nivel mundial han sido atribuidas a diferentes agentes infecciosos y uno de los más comunes es Shigella. Mundialmente se producen unos dos mil millones de casos de diarrea cada año y se consideran como la segunda mayor causa de muerte de niños menores de cinco años (OPS, 2009). A nivel de Latinoamérica y el Ecuador las enfermedades diarreicas agudas (EDA) son la segunda causa de morbilidad en la población en general y de mortalidad en niños menores de 5 años y adultos mayores (INEC, 2009). Al ser las enfermedades transmitidas por alimentos un problema de salud a nivel mundial se considera imprescindible realizar la capacitación en identificación y determinación de la sensibilidad de los antibióticos en enfermedades entéricas debido a razones epidemiológicas (OPS, 2009). en países en vías de desarrollo la circulación prevalente es de $S$. flexneri y $S$. dysenteriae; mientras que, S. sonnei y $S$. boydii son característicos en países industrializados.

En el presente estudio se observó que la especie más común es $S$. flexneri con un $64.6 \%$, seguida por S. sonnei con un $29.1 \%$, S. boydii con un $6.3 \%$ y no se reportó $S$. dysenteriae. Estos datos concuerdan con los datos publicados para Latinoamérica, especialmente estudios realizados en Brasil, Uruguay, Cuba y Argentina donde la información para la prevalencia de estas especies de Shigella es similar (Mota et al., 2005; Merino et al., 2004; Ramírez et al., 2004; Silva et al., 2008).

Durante años las enfermedades diarreicas como la shigelosis han sido tratadas mundialmente con el uso de antibióticos como trimetoprima/ sulfametoxazol, ampicilina, ciprofloxacino y azitromicina (Silva et al., 2008). Sin embargo, la 
aparición de aislados multirresistentes ha limitado el tratamiento y ha incrementado la prevalencia de la enfermedad (Silva et al., 2008). La diversidad de fenotipos de resistencia mostrados por los aislados pudiera deberse a que la resistencia de este es mediada por plásmidos, con la excepción para quinolonas y azitromicina y además por integrones o transposones que estén incorporados al cromosoma bacteriano (Ramírez et al., 2004).

Estudios competentes relacionados con la resistencia a antimicrobianos en Shigella spp. en países de Latinoamérica como Brasil, Chile, Cuba, Argentina, y Uruguay reportan una alta resistencia a los antibióticos trimetoprima/sulfametoxazol, cloranfenicol y ampicilina (Silva et al., 2008; Boehme et al., 2002; Ramírez et al., 2004; Vila et al., 1994; Mota et al, 2005). Mientras que para países como Canadá, Senegal e India se reporta una resistencia a la ampicilina y tetraciclina (Bassa et al, 2010).

Para Ecuador según Zurita (2012) el porcentaje de resistencia en Shigella flexnerii a ampicilina, tetraciclina, trimetoprima/sulfametoxazol y cloranfenicol sobrepasa el $60 \%$. Durante la vigilancia del año 2000 al 2010 no se han detectado aislamientos de Shigella resistentes a cefalosporinas de tercera generación y quinolonas. Las otras especies de Shigella como S. boydii y S. sonnei se aíslan en bajo número por lo que, no permiten sacar conclusiones de porcentaje resistencia. No se han detectado aislamientos de $S$. dysenteriae durante estos diez años de vigilancia.

En este estudio se observó una alta resistencia a tetraciclina, cloranfenicol, ampicilina y trimetoprima/sulfametoxazol lo que concuerda con los datos reportados a nivel mundial y especialmente en Latinoamérica (Bassa et al., 2010; Zurita, 2012).

Debido a que en los niños no está indicado el uso de ciprofloxacino, se recomienda alternativamente utilizar el ácidonalidíxico (Replogle et al., 2000), pero el inconveniente es que su uso genera rápidamente resistencia. La cefalosporina de tercera generación como ceftriaxona está indicada para lactantes que requieren hospitalización debido a la gravedad del cuadro clínico. En adultos y niños menores de 5 años está indicado ciprofloxacino como droga de primera elección y la azitromicina está indicada para los niños que pueden ser manejados en forma ambulatoria (Saurina et al., 2000).

En este estudio 18 aislamientos provinieron de muestras de secreción vaginal aisladas en niñas menores de 9 años. La vulvovaginitis causada por Shigella, se debe a colonización de la zona perianal por un cuadro anterior de diarrea y que por la proximidad anatómica llega a la zona genital, causa un proceso inflamatorio de la vulva y vagina acompañado de sangrado. Esto se debe a que la fisiopatología de Shigella se manifiesta de igual manera que en el epitelio intestinal, en el epitelio vaginal que está exento de estrógenos (Ocampo et al., 2014).

El género Shigella produce principalmente enfermedades diarreicas que pueden llevar a serias complicaciones debido a que las diferentes especies integrantes del género presentan factores de virulencia como genes de invasión celular, enterotoxinas y exotoxinas que afectan severamente al paciente, lo cual posteriormente en casos severos puede llevar a la muerte (Jiménez y Achí, 2009).

El gen ipaH es considerado uno de los genes más estables y presentes en todas las especies de Shigella en razón que se encuentra tanto en el cromosoma bacteriano como en múltiples copias en ADN plasmidial (Lin Thong et al., 2005) además este gen se encuentra identificado en otras bacterias patógenas como en E. coli enteropatógena, por lo que se lo considera un gen con altas características virulentas (Aranda et al, 2004). En los análisis realizados el gen ipaH fue encontrado en el $91.1 \%$ de los aislados, postulándose como el de mayor presencia dentro de los genes analizados en este estudio. La variación de este porcentaje con lo descrito por otros autores se puede deber a que las cepas negativas sufrieron mutación o deleción del gen (Silva et al., 2008). Aunque esto es muy poco probable ya que el gen se encuentra en el cromosoma bacteriano y en copias en el plásmido de invasión, estos casos se observan en cepas poco virulentas o algunas que se han mantenido en congelación por mucho tiempo como es el caso de los aislados utilizados en este estudio (Silva et al., 2008). Siete aislados $(8.9 \%)$ no presentaron el gen ipaH de estos $6(7.6 \%)$ tampoco presentaron los otros genes de estudio.

Aunque el gen ial está encargado de permitir la invasión celular, en algunos casos no se observó la presencia de éste. Tal comportamiento se debe a que el gen ial reside en una región del plásmido que es un "hot spot" para deleción espontánea (Lin Thong et al., 2005). En este estudio se comprobó esta afirmación obteniéndose una presencia del gen en los aislados estudiados del $82.3 \%$ y es el segundo gen presente dentro de los analizados en este trabajo.

En estudios anteriores autores describen que la presencia de los genes $\operatorname{set} 1 A$ y $\operatorname{set} 1 B$ juntos, únicamente se observan en la especie $S$. flexneri 
concluyéndose que estos genes se encuentran altamente conservados en esta especie (Noriega et al., 1995; Vargas et al., 1999). Según los datos recopilados en este análisis, se ratifica lo antes mencionado porque se obtuvo un $35.4 \%$ de presencia de estos genes juntos y dentro de este porcentaje el $100 \%$ de los aislados positivos pertenecen a la especie S. flexneri, es decir que al presentarse en conjunto estos dos genes únicamente en la especie $S$. flexneri se podría afirmar que esta es la única especie productora de la enterotoxina ShET-1.

La presencia de uno de los genes no indica que la cepa sea virulenta por lo que es importante evaluar los resultados globalmente (Lin Thong et al., 2005). En este estudio se formaron patrones de virulencia según los genotipos encontrados en los aislados estudiados. El patrón de virulencia con mayor presencia es el número $1(i p a H, \operatorname{set} 1 A$, set $1 B$, ial) lo que significa que la mayoría de los aislados presentan 4 de los 5 genes estudiados. Estos resultados sugieren que la mayoría de cepas aisladas son de carácter altamente virulento.

Los análisis estadísticos demostraron que existe una relación entre las especies y su patogenicidad y virulencia, así se determinó a la especie $S$. flexneri con la mayor presencia de los genes de virulencia estudiados y con la mayor multirresistencia a antimicrobianos. Las especies $S$. sonnei y $S$. boydii presentan a su vez genes de virulencia y multirresistencia pero en menor proporción que la especie S. flexneri.

Los resultados conseguidos en este estudio representan los primeros relacionados con genes de virulencia y resistencia a antibióticos en el país. En esta bacteria se observó claramente la presencia de cepas multirresistentes a antibióticos utilizados comúnmente como tratamiento primario de shigelosis, esto, combinado con la alta virulencia de las cepas, representa un problema para el control y tratamiento de esta bacteria.

\section{CONCLUSIONES}

- La mayor prevalencia se determinó en la especie S. flexneri (64.6\%), seguida de la especie S. sonnei $(29.1 \%)$ y finalmente la especie S. boydii $(6.3 \%)$. No se identificaron aislados pertenecientes a la especie S. dysenteriae.

- Los aislados de Shigella flexneri, S. sonnei y S. boydii presentaron mayor resistencia a tetraciclina, seguido de ampicilina, trimetoprima/sulfametoxazol y finalmente, cloranfenicol. Mientras que presentaron una muy baja resistencia a nitroflurantoina. No se registraron aislados de Shigella con resistencia a ciprofloxacino, azitromicina ni a ceftriaxona.

- Los genes de virulencia se encuentran en alta proporción en los aislamientos de Shigella principalmente los genes ipaH e ial. Los genes ipaH permiten la invasión y colonización del epitelio intestinal y los genes ial la formación de adhesinas e invasinas y la diseminación intercelular de la bacteria.

- Los genes set1A y set1B productores de la enterotoxina 1 ShET-1 se encontraron exclusivamente en la especie $S$. flexneri que es la especie prevalente lo que contribuye a una mayor toxicidad.

- No se encontró Shigella toxin, esto se debe que esta toxina es producida en su mayoría para la especie S. dysenteriae y en el análisis no se identificó esta especie dentro de las muestras aisladas.

\section{AGRADECIMIENTOS}

Los autores desean agradecer al grupo de trabajo del Laboratorio de Microbiología de la Escuela de Ciencias Biológicas, PUCE, Quito, a todo el personal de Zurita \& Zurita Laboratorios y del hospital Vozandes, Quito. Este estudio fue realizado con fondos del Proyecto "Diversidad Genómica y perfil de resistencia a antimicrobianos en bacterias entéricas" (Código de Proyecto G13019) y del proyecto "Genotipaje de la resistencia a antimicrobianos en bacterias entéricas" (Código G13034) financiados por la Pontificia Universidad Católica del Ecuador.

\section{REFERENCIAS BIBLIOGRÁFICAS}

Aranda K, Fagundes-Neto U y Scaletsky I. 2004. Evaluation of Multiplex PCR for Diagnosis of Infection with Diarrheagenic Escherichia coli and Shigella spp. Journal of Clinical Microbiology, 42 (12):5849-5853.

Bassa A, Dadie A, Guessennd N, Gbonon V, Dako E, Dje M y Dosso M. 2010. Virulence Factors and Resistance Profile of Shigella Isolated During Infectious Diarrhea in Abidjan, Côte D'Ivoire. Journal of Applied Sciences Research, 6 (6):594-599.

Clinical and Laboratory Standards Institute. 2015. Performance standards for antimicrobial susceptibility testing; Twenty-fifth. Informational Supplement, CLSI document. Clinical and Laboratory Standards Institute, Wayne, Pennsylvania, USA. 240 pp. 
Difco. 2011. Manual Difco Shigella Antisera Poly O. Becton, Dickinson and Company. County Clare, Ireland. pp. 11-13.

Difco. 2003. Manual of Microbiological Culture Media. BD Diagnostic Systems. USA 696 pp.

Edwards P y Edwing W. 1972. Identification of Enterobacteriaceae. Third edition. Burgers Publ. Co. Minneapolis, United States of America.

Fusano A, Noriega F, Maneval D, Chanasongcram S, Russell R, Guandalini S y Levine M. 1995. Shigella enterotoxin 1: an enterotoxin of Shigella flexneri $2 \mathrm{a}$ active in rabbit small intestine in vivo and in vitro. Journal of Clinical Investigation, 95:2853-2861.

Guerrant RL, Hughes JM y Lima J. 1999. Diarrhea in developing countries: magnitude, special setting and etiologies. Journal of Infectious Diseases Supplement, 1:S41.

Hale T. 1991. Genetic basis of virulence in Shigella species. Microbiological Reviews, 2:206-224.

Henhly H, Sheff D y Stamnes M. 1996. Shiga toxin facilitates its retrograde transport by modifying microtubules dynamics. Molecular Biology Cell, 17:4379-4389.

INEC. 2009. Anuario de Estadísticas Hospitalarias: Camas y Egresos. Diez principales causas de morbilidad. Lista Internacional DetalladaCIE-10.

Jiménez Ky Achí R. 2009. Interacciones celulares en el proceso de invasión de Shigella spp. Revista Panamericana de Infectología, 11 (2):56-61.

Klotloff KL, Winickoff JP, Ivanoff B, Clemens JD, Swerdlow DL, Sandonetti PJ, Adak GK y Levine MM. 1999. Carga mundial de infecciones por Shigella: implicaciones para el desarrollo de vacunas y la aplicación de estrategias de control. Bulletin of the World Health Organization, 77 (8):651-666.

Lin Thong K, Ling Hoe S, Puthucheary S y Yasin R. 2005. Detection of virulence genes in Malaysian Shigella species by multiplex PCR assay. Journal of Infectious Diseases, 5:5-8.

Lüscher D y Altewegg M. 1994. Detection of Shigellae, enteroinvasive and enterotoxigenic $E$. coli in the polymerase chain reaction (PCR) in patient returning from tropical countries. Molecular and Cellular Probes, 8:285-290.
Malhotra-Kumar S, Lammens C, Piessens, J y Goossens H. 2005. Multiplex PCR for Simultaneous Detection of Macrolide and Tetracycline Resistance Determinants in Streptococci. Antimicrobial Agents and Chemotherapy, 49 (11): 4798-4800.

Mandell GL, Bennett JE y Dolin R. 2009. Principles and Practice of Infectious Diseases. 7th edition. Philadelphia, USA. Chap. 224.

Merino A, Hreñuk E, Ronconi M y Alonso M. 2004. Resistencia a antibióticos y epidemiología molecular de Shigella spp. en el nordeste argentino. Revista Panamericana de Salud Pública, 15 (4):219-24.

Mota I, Varela G, Gadea M, Caffer M, Sirok A y Schelotto F. 2005. Serotipos, perfil plasmídico y antibiotipos de cepas de Shigella flexneri aisladas de niños menores de 5 años con diarrea sanguinolenta usuarios de los servicios de Salud Pública. Revista Médica de Uruguay, 21:30-36.

Noriega F, Liao FM, Maneval DR y Ren S. 1999. Formal SB and Levine M: Strategy for cross protection among Shigella flexneri serotypes. Infection \& Immunity, 67(2):782-788.

Ocampo D, Rahman, G, Giugno S, Risso P y Rubinstein A. Vulvovaginitis in a pediatric population: relationship among etiologic agents, age and Tanner staging of breast development. 2014. Archivos argentinos de pediatría, 112(1):65-74.

Organización Panamericana de la Salud. 2009. Informe Anual de la Red de Monitoreo/ Vigilancia de la Resistencia a los Antibióticos. Basilia- Brasil.

Organización Panamericana de la Salud, 2010 http: / / www.who.int/ topics / shigella / es / [Consultado 6 de agosto de 2011].

Ramírez M, Valdés N, Bravo L, Fernández Ay Castañeda N. 2004. Perfil plasmídico resistencia antimicrobiana en cepas de Shigella aisladas en Cuba. Revista Cubana de Medicina Tropical, 56(3):178-85.

Replogle M, Fleming Dy CieslakO. 2000. Emergence of Antimicrobial-Resistance Shigellosis in Oregon. Clinical Infectious Diseases, 30:515-9.

Saurina G, Quale JM y Manikal VM. 2000. Antimicrobial resistance in Enterobacteriaceae in Brooklyn, NY: epidemiology and relation to antibiotic usage patterns. Journal Antimicrobial Chemotherapy, 45:895-8. 
Silva T, Nogueira A, Magalhaes F, Fagundes A Pereira, L y Puccinelli P. 2008. Characterization of Shigella spp. by antimicrobial resistance and PCR detection of ipa genes in an infantile population from Porto Velho (western Amazon region), Brazil. Memorias del Instituto Osxaldo Cruz, Rio de Janeiro, 103 (7):731-733.

Terragno R, Caffer M y Binsztein N. 2007. Manual de procedimientos, diagnóstico y caracterización de Shigella spp. Departamento de Bacteriología. Instituto Nacional de Enfermedades Infecciosas. A.N.L.I.S. “Dr. Carlos G. Malbrán". Centro Regional de Referencia del WHO Global Salm Surv para América del Sur.

Vila J, Gascón J, Abadía S, Gómez J, Marco F y Moreno A. 1994. Antimicrobial resistance of Shigella isolates causing traveler's diarrhea. Antimicrobiological Agents Chemotherapy, 38(11):2668-70.
Vargas M, Gascon J, Jiménez de Anta M y Vila J. 1999. Prevalence of Shigella Enterotoxins 1 and 2 among Shigella Strains Isolated from Patients with Traveler's Diarrhea. Journal of Clinical Microbiology, 37 (11): 3608-3611.

WHO. 2011. 10 facts on antibmicrobial resistance. Antimicrobial resistance. Fact sheet N ${ }^{\circ} 194$. Disponible en: http://www.who.int/ mediacentre/factsheets/fs194/en/index.html [Consultado 6 de agosto de 2011].

Zurita J. 2012. Datos de Resistencia Bacteriana en el Ecuador. En: Resistencia Bacteriana en el Ecuador. 49-78. Pontificia Universidad Católica del Ecuador. Centro de Publicaciones. Quito, Ecuador. 